\title{
HISTÓRICO CONSTRUTIVO DA PONTE PIQUET CARNEIRO NO MUNICÍPIO DE ICÓ/CE
}

\author{
MELO, FRANCISCA SARA VIEIRA \\ Aluna de graduação \\ Universidade Federal Rural do Semiárido \\ Rio Grande do Norte; Brasil \\ Saravieira123vieirasara@ hotmail.com
}

\author{
SANTOS, WESLEY ARTUR MARIZ \\ Aluno de graduação \\ Universidade Federal Rural do Semiárido \\ Rio Grande do Norte; Brasil \\ Wesleyartur-tw@hotmail.com
}

\author{
NÓBREGA, MARCILENE VIEIRA \\ Professora Dra. do Magistério Superior \\ Universidade Federal Rural do Semiárido \\ Rio Grande do Norte; Brasil \\ marcilenenobrega@ufersa.edu.br
}

\section{RESUMO}

As pontes são estruturas que dão continuidade a uma via de comunicabilidade qualquer que compreende um fluxo de veículos. $\mathrm{O}$ crescimento econômico e as necessidades humanas impulsionaram um avanço tecnológico na construção civil, proporcionando um olhar mais específico principalmente nessas obras de artes. Dessa forma, surgiram técnicas que transmitiram a população uma confiança em transitar por novos caminhos. As pontes de concreto armado ganharam espaço na construção civil por possuir boa resistência à compressão e terem um tempo de vida útil considerável. Conhecendo a importância de se situar historicamente as estruturas se possa perceber a evolução de técnicas construtivas para melhorias nessas edificações. O presente trabalho teve como objetivo realizar um levantamento do histórico construtivo da Ponte Piquet Carneiro, ainda, serão mostrados métodos construtivos usuais e as respectivas dimenssões desse sistema estrutural. A ponte é localizada na entrada do município de Icó no Estado do Ceará, sobre o Rio Salgado, na rodovia federal BR - 404, que liga a cidade de Icó-CE a Piripiri-PI, considerada um patrimônio histórico na sua região. Para realização do trabalho utilizou-se referências bibliográficas de autores conceituados, o Boletim da Inspetoria disponibilizado pelo Departamento Nacional de Obras Contra a Seca (DNOCS) à época da construção da ponte. Foi observado que a ponte construída baseou-se em técnicas construtivas rudimentares, porém eficientes considerando o tempo de uso, aproximadamente 80 anos, sem ter passado por uma manutenção mais rigorosa. Este resultado apenas corrobora a importância que essas técnicas antigas têm nos projetos realizados hoje.

Palavras-chave: Levantamento Construtivo, Concreto Armado, Pontes.

\section{ABSTRACT}

Bridges are structures that provide continuity to any path of communication that includes a flow of vehicles. Economic growth and human needs drove technological advances in civil construction, providing a more specific look, especially in these works of art. Thus, techniques emerged that gave the population a confidence in moving on new paths. Reinforced concrete bridges gained space in civil construction because they have good resistance to compression and have a considerable useful life. Knowing the importance of historically locating the structures, one can perceive the evolution of construction techniques for improvements in these buildings. The present work had as objective to carry through a survey of the constructive history of the Piquet Carneiro Bridge, still, will be shown usual construction methods and the respective dimensions of this structural system. The bridge is located at the entrance of the municipality of Icó in the State of Ceará, over the Salgado River, on the federal highway BR - 404, which connects the city of Icó-CE to Piripiri-PI, considered a historical heritage in its region. To carry out the work, bibliographical references from renowned authors were used, the Inspectorate's Bulletin made available by the National Department of Works Against Drought (DNOCS) at the time of the bridge construction. It was possible to observe that the bridge built was based on rudimentary construction techniques, but efficient considering its time of use, approximately 80 years, without ever having undergone a more rigorous maintenance. This result only corroborates the importance that these ancient techniques have in the projects carried out today. 


\section{INTRODUÇÃO}

A construção de pontes sempre foi um indicativo importante para o progresso de uma civilização, uma vez que sua principal função é de transpor obstaculos. Esssas estruturas surgiram a partir de observações, quando os troncos, árvores e até mesmo grandes rochas caiam sobre percursos d'agua e formavam um elo, desta maneira foram surgindo ideias, copiadas desse fenômeno, resultando diferentes modelos entre os mais variados tipos, como de pedra, corda entre outros. A história conta ainda que as primeiras pontes surgiram após a revolução industrial e possuíam estruturas simples construídas por madeira e pedras. Em Roma, foram construídas as mais antigas pontes de pedra utilizando o método de arcos aprendida com os etruscos. (PINHO, 2007)

O crescimento econômico e as necessidades humanas impulsionaram um avanço tecnológico na construção civil, proporcionando um olhar mais específico principalmente em obras de grandes portes, foi então que começaram a aparecer técnicas que transmitissem à população uma confiança em transitar por novos caminhos. Com o início do século XX, começaram a surgir pontes de concreto armado, formadas por tabuleiros em concreto armado e com a estrutura de sustentação construídas em arcos tri articulados de concreto simples, em meados de 1912 que veio a ser utilizado o concreto armado na mesoestrutura no momento em que, as pontes constituídas por vigas e pórtico, com vão de até $30 \mathrm{~cm}$, começaram a ser construída. As pontes são consideradas obras de artes especiais principalmente as do tipo estaiadas ou suspensas, em vigas ou em arcos. (PINHO, 2007)

De acordo com Lopes Júnior (2016) no passado para solucionar sistemas complexos de projetos estruturais, os engenheiros usavam um esforço maior para encontrar respostas dos problemas, algumas vezes as soluções eram incoerentes para o comportamento real da estrutura. Atualmente nesse aspecto houve um avanço tecnológico sendo trocado o trabalho manual, como a regua de cálculo por modernos softwares.

Nas fases iniciais do projeto dessas obras de artes é realizado um estudo para à escolha dos metodos contrutivos adequados. Onde essa escolha depende diretamente, da capacidade tecnica do empreiteiro, dos prazos de execução, dos custos das diversas soluções possiveis e da segurança no processo construtivo. Dentre os precessos construtivos mais utilizados pode-se citar três principais que são: a concretagem tradicional, utilização de elementos pré-fabricados e sistema em balanços sucessivos. (HELENE, 2003)

Baseado no que foi discutido acima pode-se considerar que as pontes possuem uma evolução significativa na sua contrução, devido ao avanço nas técnicas e maior qualidade no conjunto estrutural. Sendo assim o objetivo principal deste trabalho foi realizar um levantamento do histórico construtivo da Ponte Piquet Carneiro feita de concreto armado em arco, implantada pelo Departamento Nacional de Obras Contra as Secas (DNOCS) em 1939, sobre o Rio Salgado. Como objetivo específico procurou-se realizar um levantamento das tecnicas utilizados e resaltar suas principais dimensões.

\section{DESENVOLVIMENTO}

\subsection{Fundamentação Teórica}

\subsubsection{Definição}

Baseado em estudos nessa área Pfeil, (1978), definiu ponte como sendo uma obra que tem como propósito a transposição de obstáculos, constituintes de água, que impossibilitem a passagem normal em vias de acesso, no momento em que esses empecilhos não estiverem relacionados a água, a ponte passa a ser popularmente denominado de viaduto.

A NBR 7188 (ABNT, 2013) “ carga móvel rodoviária e de pedestres em pontes, viadutos, passarelas e outras estruturas", tem uma definição análoga a Pfeil (1978), onde expõe que pontes são estruturas designada a transpor empecilhos naturais como vales, braços de mar, vales profundos entre outros, contudo ainda acrescenta que estas estão sujeitas a intervenções de cargas em movimento posicionamento distintos.

Vitório (2006), afirma que os elementos da ponte estão divididos em três regiões estruturais que são superestrutura, mesoestrutura e infraestrutura. Cada um desses elementos que constituem essas obras possui sua finalidade. Na Figura 1 pode-se observar esses elementos.Mesmo a ponte surgindo desde então para facilitar a vida humana Lopes Júnior (2016), citam os fatores negativos quanto a construção de obras desse porte, que causam grandes impactos ambientais 
com: permanente modificação da topologia do ambiente, o desequilíbrio do ecossistema devido a fortes barulhos, a alteração local da atmosfera, entre outros fatores.

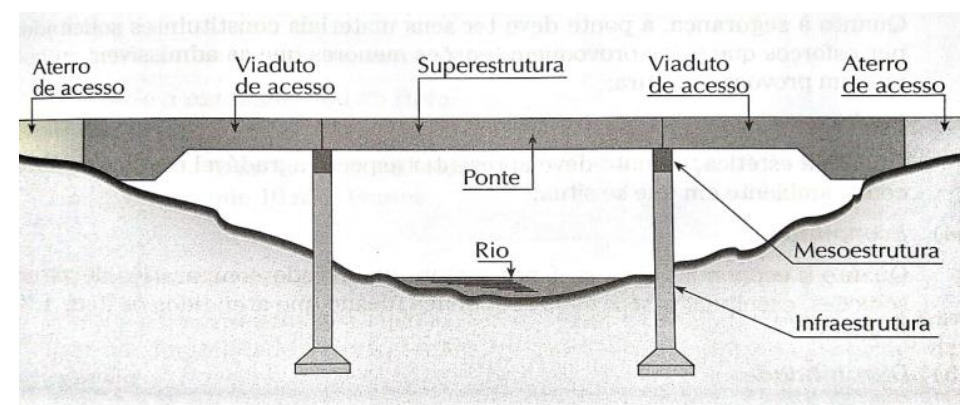

Figura 1: Elementos Estruturais de uma Ponte. Marchetti (2017)

A superestrutura pode ser denominada também de tabuleiro ou estrado, corresponde ao elemento que dá suporte a estrada, ou seja, é através dela que os veículos trafegam, a parte útil da obra, parte essa que recebe diretamente as cargas procedente do tráfego dos veículos, o estrado ou tabuleiro faz parte da mesma e é formada por vigas e lajes.(VITÓRIO, 2006)

A mesoestrutura, é o membro da estrutura que vêm a receber os esforços existentes na superestrutura e transmiti-los à infraestrutura é o componente composto por pilares. E a infraestrutura também conhecida por fundação é destinada a apoiar no terreno os esforços transmitidos da superestrutura para a mesoestrutura, é formada por blocos de estacas e tubulões (indiretas), sapatas (diretas) entre outros.(VITÓRIO, 2006)

Na figura 1 observa-se também dois elementos denominados de viaduto de acesso e aterro de acesso. Ambos são obras de acesso construídas por aterros ou viadutos, construídos quando a ponte é localizada em um vale muito aberto.

\subsubsection{Classificação dos tipos de Pontes}

Segundo Marchetti (2017), as classificações das pontes podem ser realizadas levando em consideração várias características sendo algumas as mais comuns, a extensão do vão total, a durabilidade, a natureza do tráfego, o desenvolvimento planimétrico e altimétrico, o sistema estrutural, o material, tipo estático e o tipo construtivo da superestrutura, a mobilidade dos tramos, a posição do tabuleiro.

\subsubsection{Quanto a extensão do vão}

Estruturas com vão de até 2 (dois) metros são denominados bueiros, as que possuem vãos de 2 (dois) a 10 (dez) metros são os pontilhões e as com vãos maiores que 10 (dez) metros pontes (MARCHETTI, 2017).

\subsubsection{Quanto a durabilidade}

Pontes construídas definitivamente, com durabilidade que deverá conservar-se até que forem alteradas as condições das estradas, são classificadas como pontes permanentes. As pontes provisórias, são as construídas temporariamente até que se construa a obra definitiva, na maioria das vezes servem como um desvio e as pontes desmontáveis possuem características semelhantes às provisórias, diferenciando-se apenas por serem reaproveitadas (MARCHETTI, 2017).

\subsubsection{Quanto a natureza do tráfego}

Segundo a essa classificação as pontes são nominadas das seguintes formas: pontes rodoviárias, ferroviárias, aeroviárias pontes para pedestres ou passarelas, pontes mistas e pontes canal.

As pontes rodoviárias destinam-se ao tráfego rodoviário, as pontes ferroviárias ao tráfego rodoviário, as pontes mistas ao tráfego misto de veículos e trens já as pontes passarela destinam-se ao tráfego de pedestre e a aeroviária ao tráfego de aeronaves. Dentro dessa classificação, a Ponte Piquet Carneiro, objeto de estudo desse trabalho, se encaixa como ponte rodoviária (MARCHETTI, 2017). 


\subsubsection{Quanto ao sistema estrutural da superestrutura}

As pontes nesse tópico podem ser denominadas dos seguintes tipos: Em pontes de vigas, em pórticos, em arco, pênsis e pontes atirantadas e também nos diversos tipos demonstrados na Figura 2 (MARCHETTI, 2017).

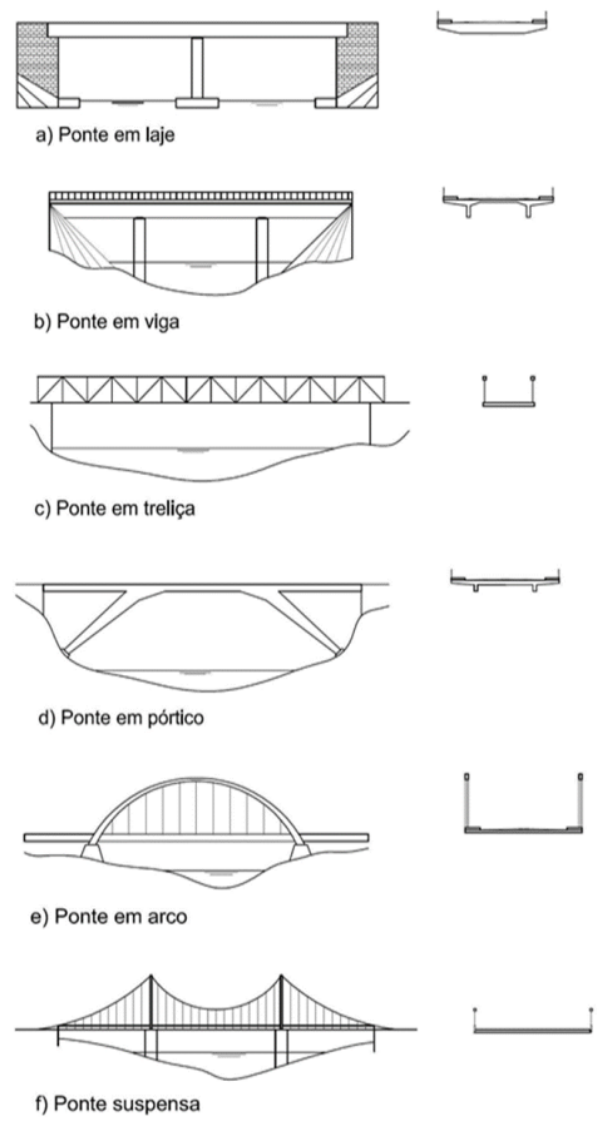

Figura 2: Tipos estruturais de ponte. Marchetti (2017)

\subsubsection{Metódo construtivo}

De acordo com Campos (2015) os métodos construtivos de pontes são divididos de acordo com seus elementos, divididos em três regiões estruturais que são superestrutura, mesoestrutura e infraestrutura. Os sistemas construtivos da infraestrutura seguem técnicas estabelecidas pela geotécnia, que de acordo com o ensaio realizado é escolhido sua fundação, para este tipo de Obra as fundações que podem ser adotadas são: Sistema de fundação por blocos de concreto, sapatas simples ou corridas, tubulhões ou por estacas.

Os sistemas construtivos da mesoestrutura, vai variar indo de acordo com a altura dos seus pilares, que podem ser executados através de peças de concretagem convencional, concretagem por segmentos, vibrada e interrompida, ou através de peças pré-moldadas, fôrmas trepantes e/ou deslizantes. (CAMPOS, 2015)

Os sistemas construtivos da superestrutura, constitui principalmente em dois, o primeiro é o sistema por caibramento, onde refere-se a uma estrutura auxiliar usada para apoiar as formas da estrutura da Ponte, após a execução da concretagem da estrutura da Ponte. E o segundo é o processo dobre escoramentos, que pode ser formado por escoramento fixo ou pela combinação de escoramento móvel. (CAMPOS, 2015)

Ao analisar os processos construtivos de uma obra, surgem indagações sobre os diversos lugares e suas adversidades, quando a obra se trata de uma ponte, os processos de construção precisam ser específicos ou que seja de extrema necessidade para com o seu projeto. Na diferença da composição estrutural as pontes de concreto armado diferem de outras obras por alguns fatores específicos como: a carga de utilização, as necessidades de vencer vão, 
processo de construção, diferenças quanto a analise estrutural. Na análise estrutural por sua vez apresenta formas de simplificar e recomendações em função da composição estrutural. (DEBS; TAKEYA, 2009)

\subsubsection{Características geométricas das pontes}

Segundo o autor, Pfeil (1979), a armação de uma ponte é constituída por uma variedade de elementos geométricos dentre eles pode-se citar os seguintes elementos da seção transversal:

- Tramo de uma ponte - É um componente da superestrutura que se encontra posicionada entre dois elementos subsequentes da mesoestrutura.

- Vão teórico - O vão teórico do tramo de uma ponte é a distância horizontal existente entre o meio de dois apoios seguidos.

- Vão livre - O vão livre do tramo difere do vão teórico do tramo, pois, a distância horizontal medida nesse caso é entre os parâmetros de pilares e encontros ou entre dois pilares.

- Altura da construção - é a distância vertical medida entre o ponto mais alto da superfície do estrado e o ponto mais baixo da superestrutura, na seção determinada. (Figura 2)

- Altura livre - é a distância verticalmente medida entre o ponto mais baixo localizado na superestrutura e o ponto mais alto do empecilho transposto pela ponte na seção determinada. (Figura 2)

- Gabarito - é o agrupamento de espaços livres que deve ter na seção transversal da ponte, para que a mesma possa cumprir sua utilidade, sendo definido por uma largura livre assim como por uma altura livre. (Figura 3)

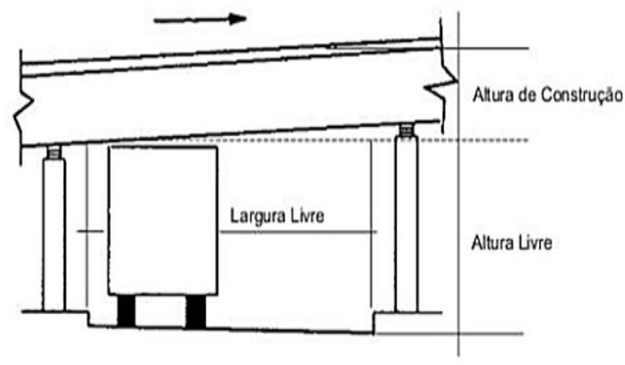

Figura 3: Altura de construção e gabarito da estrutura. Almeida e Souza (1997)

- Esconsidade - A ponte denomina-se ponte oblíqua ou esconsa, é, mais usual a segunda denominação, quando o eixo longitudinal desta não forma um ângulo reto com o eixo longitudinal do obstáculo transposto. A ponte é denominada esconsa à direita ou à esquerda quando seu eixo longitudinal tende para a esquerda ou para direita perpendicular ao eixo longitudinal do obstáculo transposto, como está ilustrado na Figura 4.a e 4.b.
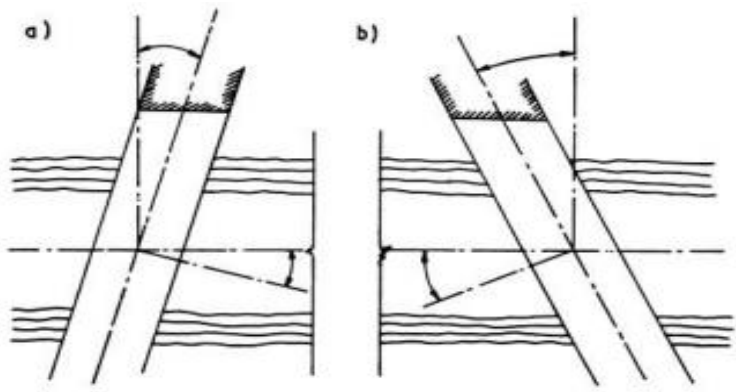

Figura 4: Ilustração da esconsidade à direita (a) ou à esquerda (b). A esconsidade é o ângulo. Pfeil (1979) 


\subsubsection{Contextualização Histórica}

De acordo com Jesus, (2013) as formas técnicas, assim como materiais que utilizamos na contrução civil atualmente são diferentes quando comparados com antigamente. Observou-se a diferença entre os estilos de cada época. Por exemplo, no periodo romano foi onde nasceram as pontes em arco de pedra que possuiam até 30 metros e foram reflexos para as pontes atuais que atendem o formato de arco, algumas dessas contruções vem sendo preservadas ainda nos dias de hoje.

Com base no mesmo autor, no período medieval, o início da Idade Média foi marcado pelo atraso do império romano, onde caiu também em desuso à rede de estradas, deixando as pontes em um período de paralisação, tendo como consequência a capacidade dos profissionais desta área diminuindo. Ainda nessa época, no ponto de vista do estudo das pontes medievais, conclui-se que os monges foram grandes contrutores e conseguiram por anos conservar as obras romanas.

Em um momento posterior no periodo da Idade Moderna, conhecida como Renascimento que vai do século XVI até o XVII depois de Cristo, uma fase de conflito e reformulação de conhecimentos passasdos, logo essa fase ficou marcado por introduzir novas formas geométricas diferenciadas nas estrutura arquitetônica (JESUS, 2013).

Com a revolução industrial, que teve inicio na Inglaterra no final do século XVII, expandiu-se significativamente provocando na construção civil um avanço satisfatório e as pontes passaram a ser de estruturas metálicas, porém com o seu custo elevado, o concreto armado conseguiu ganhar espaço (JESUS. 2013).

\subsection{Materiais e Métodos}

\subsubsection{Local da pesquisa}

O trabalho foi realizado na Ponte Piquet Carneiro localizada na entrada do município de Icó no Estado do Ceará, sobre o Rio Salgado, na rodovia federal BR - 404, que liga a cidade de Icó-CE a Piripiri-PI, a mesma conta com três pares de arcos parabólicos tri articulados de $40 \mathrm{~m}$ de corda e $8,30 \mathrm{~m}$ de flecha, largura igual a $50 \mathrm{~cm}$, com uma extensão total de 150 m e uma largura de $8,90 \mathrm{~m}$. Na Figura 5 ilustra-se a localização da ponte.

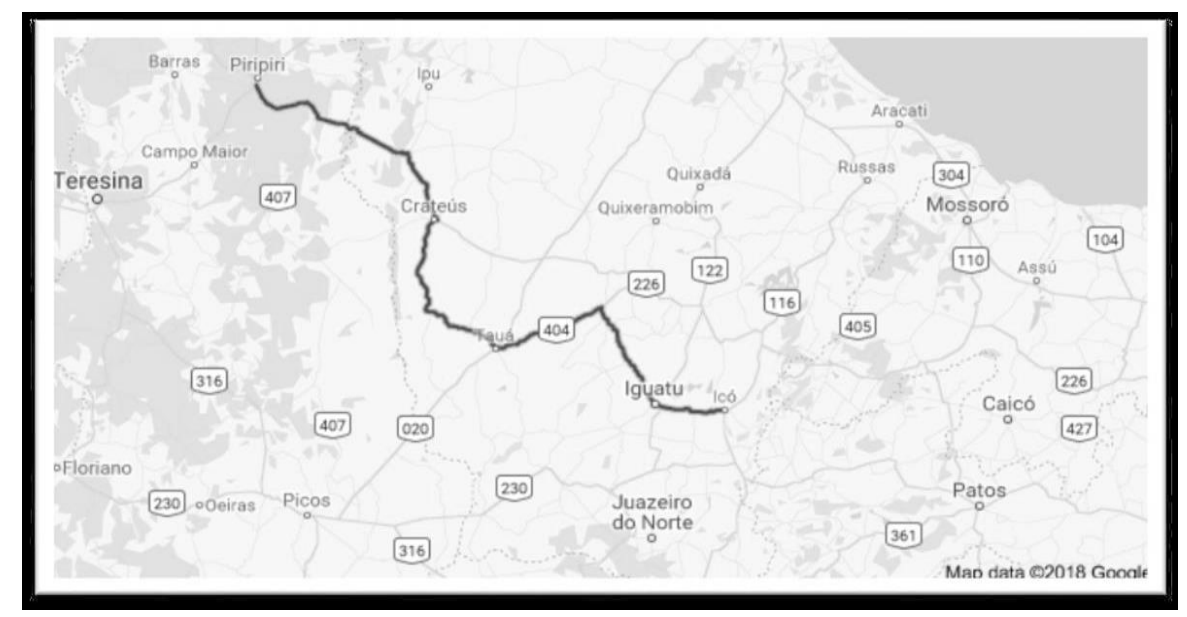

Figura 5: Localização da BR - 404. Google (2018)

\subsubsection{Levantamento do histórico construtivo da Ponte Piquet Carneiro}

Para realização dessa etapa do trabalho foi feito uma pesquisa bibliográfica em órgãos públicos e conversas com historiadores da região.

\section{RESULTADOS E DISCUSSÕES}

Segundo o historiador local, Altino Afonso de Medeiros, a cidade de Icó/CE tem sua fundação com o extermínio dos índios, os tapuias, e com a chegada dos brancos portugueses, por volta de 1682. Também é conhecida por ser uma cidade praticamente toda tombada pelo Instituto do Patrimônio Histórico e Artístico Nacional (IPHAN). 
Segundo o mesmo, a cidade foi atingida por uma seca que repercutiu na economia da cidade no final do século XIX. Preocupada com a população local, os governantes resolveram solicitar a construção de obras destinadas para a população atingidas pela forte seca ao presidente da Província, porém não teve sucesso.

No início do século XX essa situação piorando-se agravou, pois, a estrada de ferro que passaria pela cidade, não passou mais, assim ao longo do século XX Icó enfrentou uma grande crise até que alguns comerciantes importantes se instalaram na cidade com o sistema algodoeiro, com isso também foi aumentando a indústria local de algodão, então surgiu a necessidade da abertura de novas estradas.

Nas décadas de vinte e trinta, com a difusão do automóvel, abrem-se estradas e consequentemente a construção da Ponte Piquet Carneiro, que por sua vez mudou completamente a posição da cidade diante a economia local e regional. Pelas características próprias de sua estrutura e pelos processos de construção empregados na sua execução, pode-se denominar essa ponte como uma obra de utilidade social e econômica ao mesmo tempo ornamental. A mesma pode ser considerada um verdadeiro ponto de articulação da região centro sul do Ceará por possuir uma localização central.

A Ponte Piquet Carneiro é uma obra em concreto armado, implantada pelo Departamento Nacional de Obras Contra as Secas (DNOCS) em 1939.

Primeiro passo para a construção da Ponte foi a análise e preparação do seu terreno, verificando se o mesmo era firme o suficiente para receber os pilares e alicerce. Então foi realizada uma sondagem com processos rudimentares, porém suficientes para escolha correta da localização. Foi localizado a 16m de profundidade o material resistente para apoio direto das fundações, a escolha da estrutura foi feita visando uma maneira de atender as necessidades e reduzir os gastos, então foi diminuído o número de pilares, a extensão total da ponte foi dividida em três partes iguais de $50 \mathrm{~m}$ para cada.

A construção da mesma teve início no dia 3 de julho de 1937, com a concretagem das estacas. Logo em seguida começou pelo encontro da margem esquerda, cravadas com diversas estacas. Na Figura 6 (a) pode-se observar detalhes de parte desse processo. No encontro da margem direita, as pontas das estacas encontraram terreno firme a uma profundidade média de $9 \mathrm{~m}$. Na Figura 6 (b) vê-se o encontro da margem direita vendo-se a betoneira e bomba de concreto com a tubulação instalada para a concretagem do pilar.
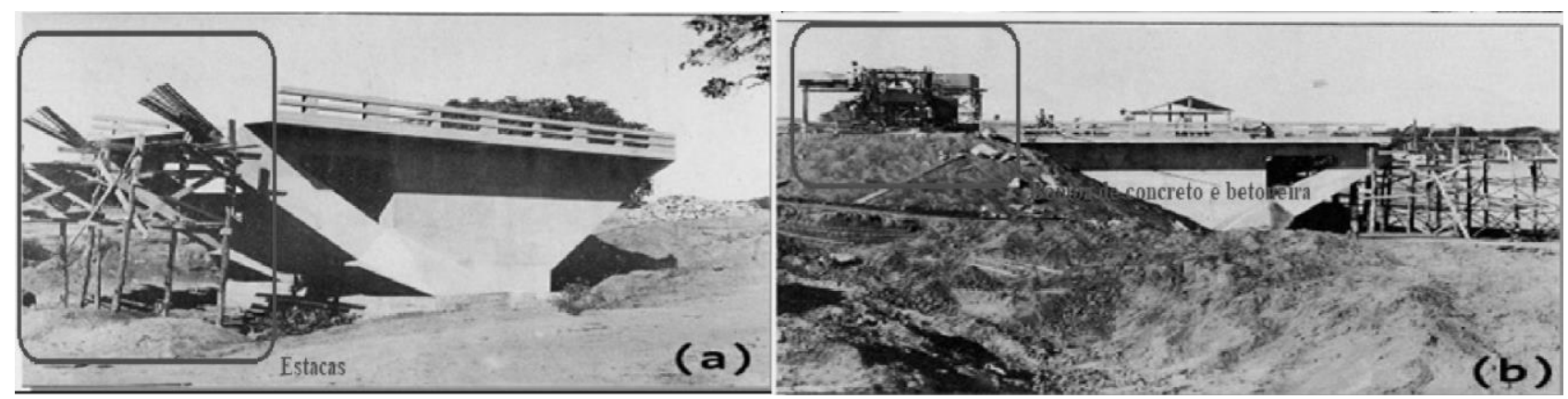

Figura 6: Parte construtiva da Ponte (a) Encontro da margem esquerda (b) Encontro da margem direita, vendo-se equipamentos para auxilio da construção. Adaptada de DNOCS (1939)

Sua estrutura conta com três pares de arcos parabólicos tri articulados de $40 \mathrm{~m}$ de corda e $8 \mathrm{~m}$ e $30 \mathrm{~cm}$ de flecha, tem suas articulações nas nascenças e no fecho, essas articulações são formadas por um feixe de 20 barras de ferro redondo em "I" com 3m de comprimento curvadas de modo a tenderem as extremidades para o centro, ligadas por estribos e devidamente soldadas, as das nascenças possuem um feixe de 22 vergalhões de "I" com $4 \mathrm{~m}$ e duas barras de ferro ligadas também por estribos e soldados, estruturação semelhante às do fecho, a largura dos arcos é constante e igual 50 $\mathrm{cm}$ e a espessura crescente do fecho é de $1 \mathrm{~m}$ para nascenças onde chega a 1,30 m. A Figura 7 ilustra a construção de um dos $\operatorname{arcos}(\mathrm{a})$ que formam a estrutura e os três arcos juntos (b). 

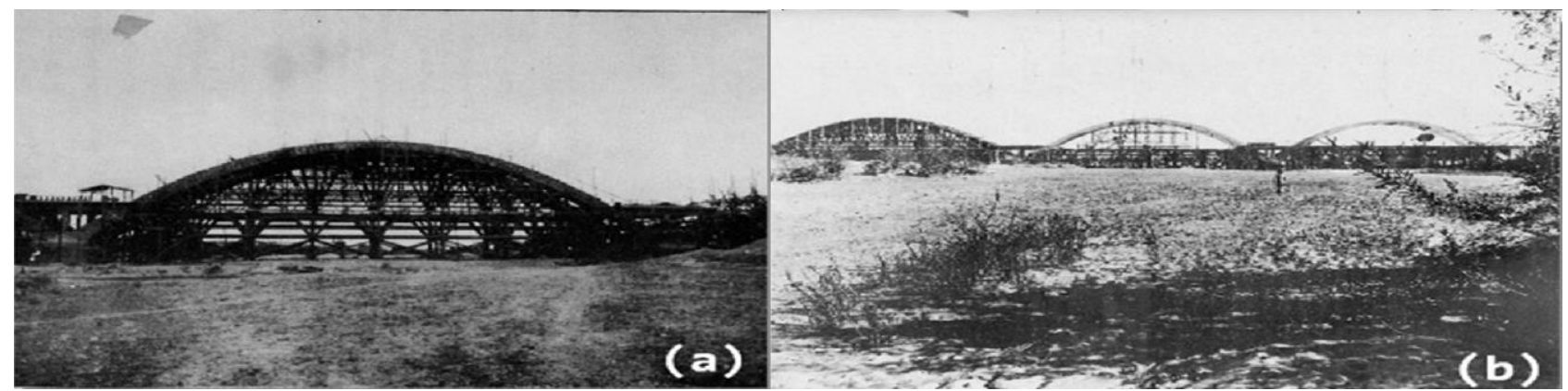

Figura 7: Construção dos arcos (a) andaime para escoramento do arco central; (b) Aspecto da construção depois de terminada a concretagem dos arcos da margem esquerda. DNOCS (1939)

As suas armaduras são formadas por vergalhões de formato em "I" e estribos retangulares de 7,94 mm, na lateral existe quatro peças retangulares com $60 \mathrm{~cm}$ de largura e $40 \mathrm{~cm}$ de espessura. No meio e nas extremidades de cada vão, a laje do estrado possui uma junta de dilatação com $20 \mathrm{~mm}$ de intervalo cheio por asfalto, a espessura desta laje é de $15 \mathrm{~cm}$ na via de rodagem, já na via de passeio lateral possui $10 \mathrm{~cm}$, existindo ainda uma diferença de nível que corresponde a 18 $\mathrm{cm}$ entre os dois pisos. A mesma ainda é composta por uma longarina central de $20 \times 50 \mathrm{~cm}$, dois longerões de $30 \times 88 \mathrm{~cm}$, distantes $3 \mathrm{~m}$ do seu eixo e travessas de $25 \times 60 \mathrm{~cm}$ com espaços entre si de $3,63 \mathrm{~m}$ que se prolongam além dos longerões junto de $1,30 \mathrm{~m}$ de balanço com altura decrescendo.

A estrutura dos pilares é formada por dois pares de peças inclinadas, utilizadas na direção da tangente do arco na nascença, com uma seção constante igual à dos arcos na nascença e contra ventadas lateralmente. Existe uma coluna central que oferece um apoio intermediário ao longerão e travessa da parte do estrado.

Nos encontros existem uma sapata de 2,35m de altura com uma base de 6,00x9,00m firmada em estaca e para completar sua estrutura são empregadas cortinas de testa e laterais constituídas por lajes de $25 \mathrm{~cm}$ de espessuras, nervurada as laterais, por colunas de $40 \mathrm{x} 40 \mathrm{~cm}$, sobre elas também se apoiam as travessas do estrado sobre os encontros, com alas de $10,00 \mathrm{~m}$ de comprimentos dos quais $4,00 \mathrm{~m}$ encontra-se em balanço.

Nas fundações de encontros e pilares foram cravadas 150 estacas de concreto armado com 13,00m de comprimento e uma seção de 30x30cm armadas com 4 vergalhões em "I" conectados por uma espiral de ferro.

A ponte de maneira geral possui uma extensão total de $150 \mathrm{~m}$ de comprimento e $8,90 \mathrm{~m}$ de largura do qual torna-se útil $8,50 \mathrm{~m}$, onde $5,50 \mathrm{~m}$ é destinado para via de rodagem e $3 \mathrm{~m}$ para ambos os passeios laterais (destinados $1,5 \mathrm{~m}$ para cada lado) a mesma ainda é constituída por uma laje nervurada por dois longerões, uma longarina e travessas, apoiadas sobre dois pilares numa extensão de $50 \mathrm{~m}, 10 \mathrm{~m}$ sobre cada pilar, e apoiadas também sobre as estruturas dos encontros, $15 \mathrm{~m}$ sobe cada encontro, numa extensão total de $120 \mathrm{~m}$. As Figuras 8,9 e 10 mostram a ponte finalizada na época (a) e atualmente (b), de diferentes ângulos.

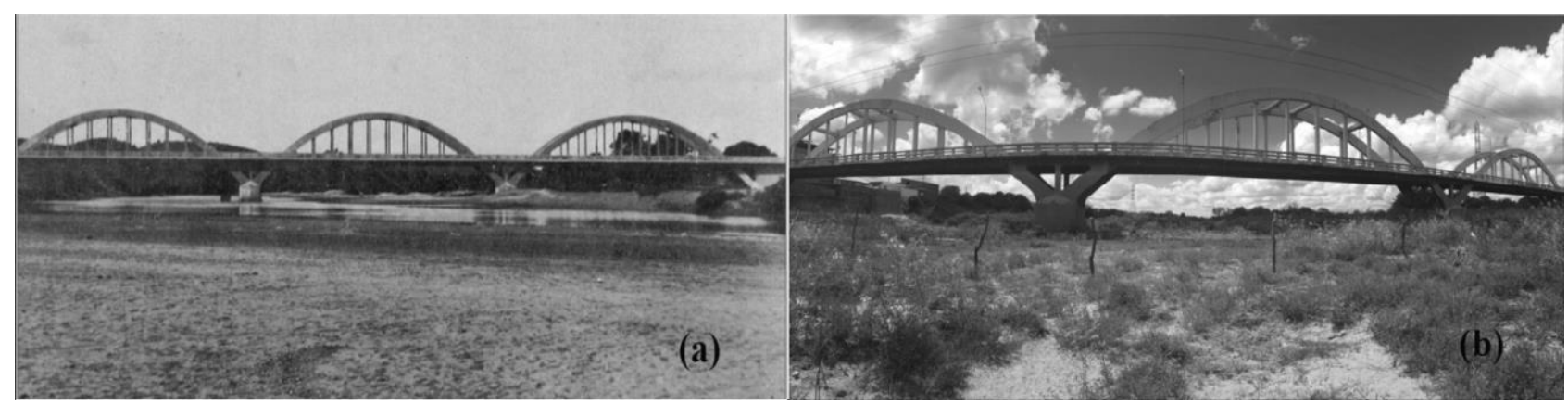

Figura 8: Vista da ponte concluída (a) no ano de 1939; (b) no ano de 2019. Adaptado do DNOCS (1939) 


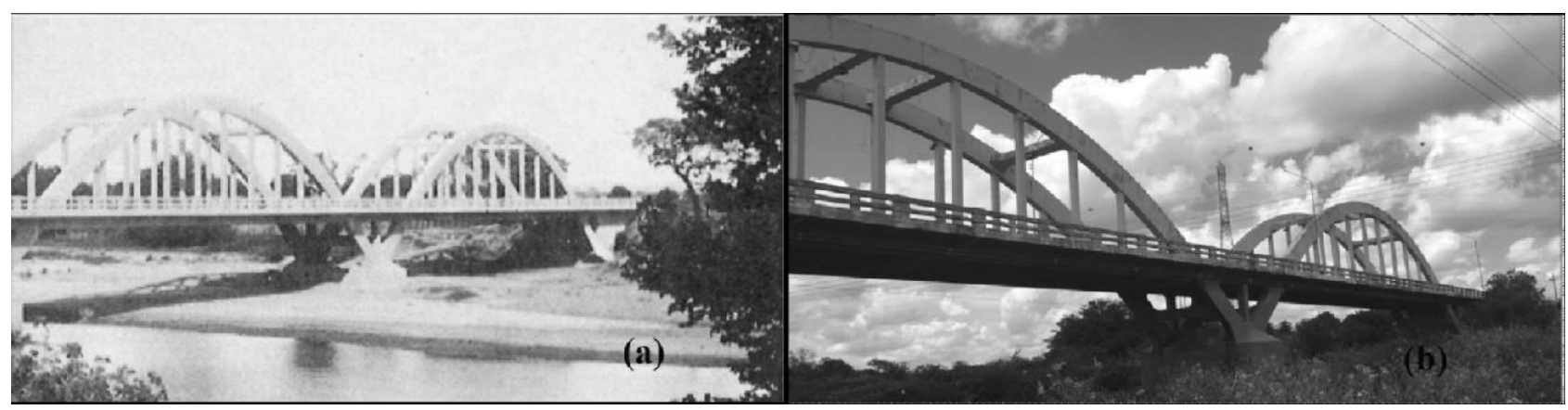

Figura 9: Vista da ponte concluída (a) no ano de 1939; (b) no ano de 2019. Adaptado do DNOCS (1939)

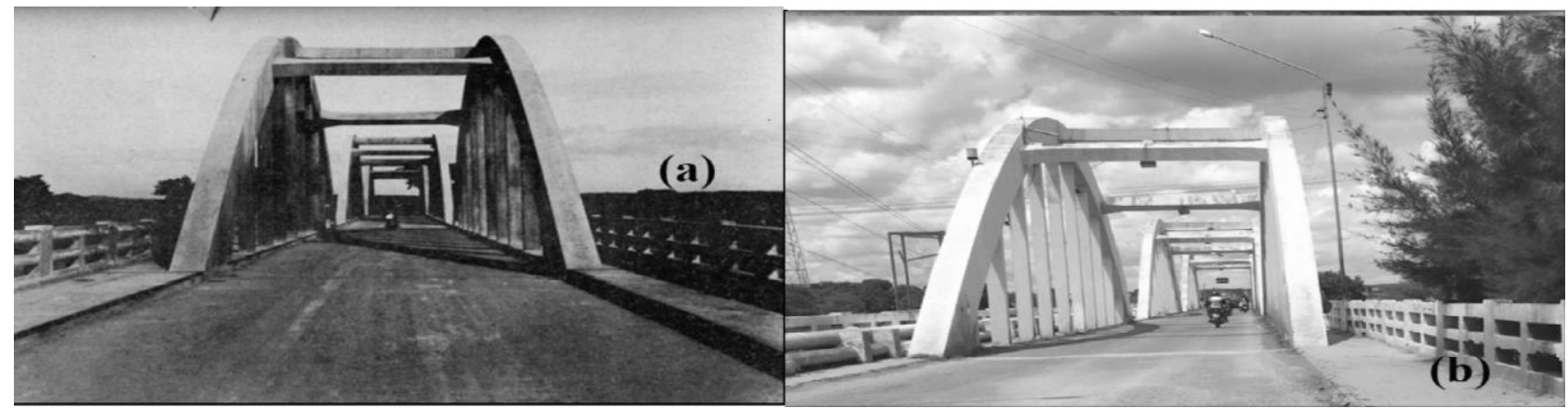

Figura 10: Vista da ponte concluída, colhida do encontro da margem direita (a) no ano de 1939; (b) no ano de 2019. Adaptado do DNOCS (1939)

\section{CONCLUSÕES}

A partir da pesquisa realizada com relação aos aspectos construtivos da ponte e pode-se considerar que:

- O processo de execução da fundação consistiu na realização de uma sondagem com processos rudimentares, porém suficientes para escolha correta da localização.

- Mesmo sendo considerados processo rudimentares, foi encontrado material resistente a $16 \mathrm{~m}$ de profundidade para execução dos apoios das fundações;

- Na época da construção da ponte já existia por parte dos construtores atenção especial com relação a economia e seguração das edificações. Esse fato se refletiu na escolha da estrutura em que foi reduzido o número de pilares sem comprometimento estrutural da edificação;

- Para melhor acomodação das cargas a extensão total da ponte foi dividida em três partes iguais de $50 \mathrm{~m}$ para cada;

Após a realização do trabalho percebeu-se que a Ponte Piquet Carneiro localizada na entrada do município de Icó no Estado do Ceará, pode ser considerada um verdadeiro ponto de articulação da Região Centro Sul do Ceará por possuir uma localização central e possui uma importância fundamental, não só econômica e social , mas é um registro real da evolução das tècnicas construtivas para a época, pois a mesma possui diversos elementos construtivos ainda utilizados até hoje na engenharia e continua sem reparos a mais de 80 anos após sua construção.

\section{REFERÊNCIAS}

ASSOCIAÇÃO BRASILEIRA DE NORMAS TÉCNICAS. NBR 7188: Carga móvel rodoviária e de pedestres em pontes, viadutos, passarelas e outras estruturas. 2 ed. Rio de Janeiro, 2013

CAMPOS, Alan Rocha. Método de construção de Pontes e Viadutos: Estudo de caso. 2015. 64 f. Monografia (Especialização) - Curso de Engenharia Civil, Centro Universitário do Distrito Federal - Udf, Brasilia, 2015. 
D’ORSI SOBRINHO, Rodrigues. Ponte Piquet Carneiro, Boletim de Inspetoria Federal de Obras as Secas, Rio de Janeiro, v.11, n.2, p.141-149, abr.-jun. 1939

D’ORSI SOBRINHO, Rodrigues. Ponte Piquet Carneiro, Boletim de Inspetoria Federal do Departamento Nacional de Obras as Secas(DNOCS), Rio de Janeiro, v.11, n.2, p.141-149, abr.-jun. 1939

EL DEBS, M. K.; TAKEYA, T. Pontes de Concreto. São Carlos, USP - Universidade São Paulo, 2009. Notas de aula HELENE, Paulo R. Do Lago. Manual de reparo, proteção e reforço de estruturas de concreto. São Paulo, Red Rehabilitar, 2003.

JESUS, J.J.C. Caraterização Geométrico-Estrutural de Pontes em Arco de Alvenaria na Região de Bragança. São Paulo: Instituto Politécnico de Bragança, 2013.

LOPES JÚNIOR, Marcelo Sérgio Couteiro; LOPES, Marcileia Couteiro. Impactos da construção da Ponte sobre o Rio negro, no cotidiano dos produtores rurais da comunidade nova esperança - Iranduba/AM. In: ASSOCIAÇÃO NACIONAL DE PÓS-GRADUAÇÃO E PESQUISA EM AMBIENTE E SOCIEDADE MANAUS, 1., 2016, Amazônia. Anais... . Amazônia, 2016. p. 1 - 27.

MARCHETTI, Osvaldemar. Pontes de concreto armado. São Paulo: Blucher, 2017. 237 p.

PFEIL, Walter, 1979. Pontes Em Concreto Armado: Elementos De Projetos, Solicitações, Dimensionamentos. Livros técnicos científicos editora S.A. Rio de Janeiro

PINHO, Fernando Ottoboni, BELLEI, Ildony Hélio, Pontes e viadutos em vigas mistas, $1^{\mathrm{a}}$ ed. Rio de Janeiro, IBS/CBCA, 2007

VITÓRIO, J. A. P. Vistorias, Conservação e Gestão de Pontes e Viadutos de Concreto. Anais do $48^{\circ}$ Congresso Brasileiro do Concreto, 2006. 